\title{
Fruit Production Planning in Semiarid Zones: A Novel Triangular Intuitionistic Fuzzy Linear Programming Approach
}

\author{
Sajida Kousar $\left(\mathbb{D},{ }^{1}\right.$ Afia Zafar $\left(\mathbb{D},{ }^{1}\right.$ Nasreen Kausar ${ }^{(D)},{ }^{2}$ \\ Dragan Pamucar $\mathbb{D}^{3}$ and Parameshwari Kattel $\mathbb{D}^{4}$ \\ ${ }^{1}$ Department of Mathematics and Statistics, International Islamic University, Islamabad, Pakistan \\ ${ }^{2}$ Department of Mathematics, Faculty of Arts and Sciences, Yildiz Technical University, Esenler, Istanbul 34210, Turkey \\ ${ }^{3}$ Department of Logistics, University of Defence, Belgrade, Serbia \\ ${ }^{4}$ Department of Mathematics, Tri-Chandra Multiple Campus, Tribhuvan University, Kathmandu, Nepal
}

Correspondence should be addressed to Parameshwari Kattel; parameshwari.kattel@trc.tu.edu.np

Received 13 November 2021; Accepted 11 January 2022; Published 12 February 2022

Academic Editor: Cristiano Fragassa

Copyright ( 2022 Sajida Kousar et al. This is an open access article distributed under the Creative Commons Attribution License, which permits unrestricted use, distribution, and reproduction in any medium, provided the original work is properly cited.

\begin{abstract}
A triangular intuitionistic fuzzy linear programming (TIFLP) model is formulated for the planning of sustainable fruit production system for hyperarid regions while assuming the availability of resources and existing knowledge. A remarkable advancement is achieved through the composition of intuitionistic fuzzy concept with the linear programming by considering all parameters and variables in the form of triangular intuitionistic fuzzy numbers, which provides a planning or strategic tool for handling uncertain situations with more control and in a realistic way. This fuzzy optimization model is redesigning the feasible region obtained by linear programming which is presented in graphical form. Moreover, the practical application and implementation of this fruit production system for planning in real-life scenarios are accomplished considering the case study of fruit orchards of Baluchistan, Pakistan.
\end{abstract}

\section{Introduction}

Have you ever imagined experiencing the world without agriculture? In that case, most of the world's population could not outlive hunger, and the remaining ones would be hunting for food. In fact, you would no longer be here to read this paper because the path of modern civilization would be lost forever with the absence of agriculture. Agriculture is art, science, and business of all types of crop production which flourished into seven major branches named as agronomy, horticulture, forestry, animal husbandry, agricultural engineering, fishery, and home science [1]. The beginning of human civilization started with agricultural development referred to as first agricultural revolution. Later on, agriculture and farming spread into different regions around the world and broadened with livestock, industrial agriculture, agronomy, and much more. The history of human civilization is reflected by the inventions, methods, and techniques used to enhance the agriculture and its different branches in a productive manner. Throughout modification in agricultural field, it has been improved and transformed into much more ultramodern form known as "sustainable agriculture" which equally impacts the environment, society, and economy [2].

The ultimate motive of sustainable agriculture is the satisfaction of all human needs and necessities with the major contribution to economy in healthy environmental conditions. The improvement of our food security system is the mostly targeted goal for the betterment of present and future generation. The sustainable development goal is the eradication of hunger by accomplishing food security and improving the nutrition intake by 2030 [3]. A thorough analysis was carried out about the achievement of "zero hunger" goal by studying all the existing scientific literature to assess their contribution to the achievement of the sustainable development goal [4]. According to a latest study, the fourth agricultural revolution demands the balance between the agricultural production and world's population 
together with the environment [5]. To eradicate the undernourishment of the world, fruit consumption rate of the world per capita should be according to diverging health conditions. The low intake of fruit and vegetable increases the worldwide burden of disease, which can be controlled through the ample amount of fruit consumption and production [6]. Analytical study reveals that approximately $22 \%$ of difference exists between the demand and supply of fruit production, whereas this percentage increases to $58 \%$ for the underdeveloped countries, which is increasing with the passage of time [7].

Pakistan, being a middle-income developing country, produces five major crops, wheat, rice, sugarcane, maize, and cotton, along with the most importantly fruits and vegetables with pulses and oilseeds [8]. The production of fruits and vegetables is approximately 12 million tons per year. More precisely, fruits contribute $2.48 \%$ to agricultural gross domestic product of Pakistan, producing apples, mangoes, grapes, dates, citrus, peaches, cherries, plums, loquat, pears, and guava. According to a rough analysis, Pakistan earned $\$ 730$ million by exporting 1.165 million tons of fruits and vegetables in a year [9]. The study of Pakistan recommends investing in research and development to find innovative strategies to enhance production and quality and reduce postharvest losses in order to boost fruit and vegetable export competitiveness [10]. The global horticultural products trade for the past two decades was maximized by four times by making earnings of USD 51 billion in 2001 to USD 200 billion in 2018 [11]. The international trade competitiveness of Pakistan is evaluated through the analysis of competitive and comparative demand and supply of vegetables and fruits [12]. The overwhelming pressure on the demand of food security caused by population increase and global development results in the destruction of natural resources and food crises [13]. Additionally, COVID-19 and intense climate changes severely escalate the demand of food by decreasing the average agricultural production [14].

Real-life situations can be assessed mathematically. For modeling and management of certain scenarios, mathematical analysis of real-life occurrences utilized quantitative and qualitative methodologies. Linear programming is a generalized and renowned technique presented by Kantorovich [15] to optimize agricultural aims and objectives by allocation and restriction of certain demand and availability constraints [16]. In light of our current agricultural requirements, our objective is not only food supply but also the ample amount and quality of food provision around the world. Therefore, agricultural planning is carried out for this goal using operational mathematical approaches in the most efficient way in order to eliminate food security issues $[17,18]$. It is used as a single objective as well as multiple objectives to minimize and maximize the cost and profit by the utilization and management of natural resources, labor, techniques, research, capital regarding land allocation, cropping patterns, optimization of water resources, raising livestock, and production maximization with cost minimization [19].

Food production system must be thoroughly modified and armed with resilience and adaptivity and have high diversity against different situations and factors (climate change, pest attacks and diseases, governmental policies at national and international level, social and cultural stability factors) [20]. For perfection in the precision of goals regarding planning, this area still needs much more modifications in terms of changing environmental, ecological, and social factors [21]. Globally, agricultural output continuously confronts drastic fluctuations due to which sustainable agriculture is constantly evolving with the passage of time and demand of the world is changing continuously regarding various aspects. These factors generate uncertainly and vagueness in environment, which is assessed by using the concept of fuzzy sets introduced by Zadeh [22]. Indeed, fuzzy set and its generalizations such as intuitionistic fuzzy sets [23] are utilized to present data that is fuzzy in nature. Eventually, fuzzy optimization theory was initiated by Zimmermann for effective decision making in fuzzy environment [24].

Fuzzy linear programming approach was further investigated through meticulous application to decision making and management problems considered in uncertain environment, and it obtained much more precise and feasible output [25]. Under unpredictable circumstances in energy-water nexus, an integrated fuzzy optimization approach was proposed for agricultural water and land resource management [26]. Multiobjective fuzzy methodology having three goals was considered as maximization of net benefits, agricultural output, and labor employment for Pune city of Maharashtra State, India [27]. Another study was conducted by applying intuitionistic fuzzy optimization technique in agricultural production planning, with a focus on smallholder farmers in north Bihar, India [28].

Specifically, fruit production planning by using linear programming is done, which is generalized for production maximization in hyperarid regions with available resources, labor, capital, etc. Further, in order to evaluate a targeted objective function that stays valid and optimal under the influence of climatic, social, and economic conditions, triangular intuitionistic fuzzy linear programming has been constructed more accurately and meticulously. The article is divided into five sections, where all the basic and essential information is provided in Preliminaries section. The objective function and constraints for optimal fruit production in crisp and intuitionistic fuzzy environment are defined in Methodology section. The model is then applied to a real-life example by considering fruit production data from Baluchistan province of Pakistan. The superiority of the proposed methodology is supported by comparative and postoptimal analysis.

\section{Preliminaries}

2.1. Fuzzy Set. Let $X$ be the universal set. A fuzzy set $\widetilde{A}$ [22] consists of a pair defined as $\widetilde{A}=\left\{\left(x, \mu_{\tilde{A}}(x)\right), x \in X\right\}$, in which the first element $x$ of $\left(x, \mu_{\tilde{A}}(x)\right)$ belongs to classical set and the second element defined as $\mu_{\tilde{A}}(x): X \longrightarrow[0,1]$ refers to the membership degree of $x$ in $\tilde{A}$, called the membership function of $\widehat{A}$. 
2.2. Fuzzy Intuitionistic Sets. Let $X$ be denoted as a universal set. An intuitionistic fuzzy set (IFS) $\widetilde{A}^{I}$ [23] is defined as set of ordered triplets $\widetilde{A}^{I}=\left\{\left(x, \mu_{\mathcal{A}}^{I}(x), \nu_{\mathcal{A}}^{I}(x)\right) ; x \in X\right\}$, in which the functions $\mu_{\widetilde{A}}^{I}(x): X \longrightarrow[0,1]$ and $v_{\widetilde{A}}^{I}(x): X \longrightarrow[0,1]$ represent membership and nonmembership degree of $x$ in $\widetilde{A}$, respectively, for each element $x \in X$ satisfying $0 \leq \mu_{\widetilde{A}}^{I}(x)+v_{\widetilde{A}}^{I}(x) \leq 1$.

2.3. Triangular Intuitionistic Fuzzy Number. A triangular intuitionistic fuzzy number (TIFN) [29] $S$ is an especial IFN with the membership function and nonmembership function defined as follows:

$$
\mu_{S}(x)= \begin{cases}0, & \text { if } x<a, \\ \frac{x-a}{b-a}, & \text { if } a \leq x \leq b, \\ 1, & \text { if } x=b, \\ \frac{c-x}{c-b}, & \text { if } b \leq x \leq c, \\ \nu_{S}(x)= \begin{cases}\frac{1,}{1,} & \text { if } x>c, \\ \frac{b-x}{b-d}, & \text { if } d \leq x \leq b ; \\ 0, & \text { if } x=s_{2}, \\ \frac{x-b}{e-b}, & \text { if } b \leq x \leq e, \\ 1, & \text { if } x>e,\end{cases} \end{cases}
$$

where $d \leq a \leq b \leq c \leq e$, denoted by $\stackrel{-I}{S}=(a, b, c ; d, b, e)$ or TIFN. Membership and nonmembership functions of TIFN are presented in Figure 1.

2.4. Accuracy Function. The accuracy function [30] for triangular intuitionistic fuzzy numbers $A=\left(a_{1}, a_{2}, a_{3}\right.$; $\left.a_{1}^{\prime}, a_{2}, a_{3}^{\prime}\right)$ is defined as

$$
H\left(\breve{A}^{I}\right)=\frac{\left(a_{1}+2 a_{2}+a_{3}\right)+\left(a_{1}^{\prime}+2 a_{2}+a_{3}^{\prime}\right)}{8} .
$$

\section{Operations on Triangular Intuitionistic Fuzzy Number}

A triangular intuitionistic fuzzy number $\stackrel{-I}{S}=\left(s_{1}, s_{2}, s_{3}\right.$; $\left.s_{1}^{\prime}, s_{2}, s_{3}^{\prime}\right)$ is said to be nonnegative if and only if $s_{l}^{\prime} \geq 0$.

The arithmetic operations of triangular intuitionistic fuzzy number [29], i.e., addition, subtraction,

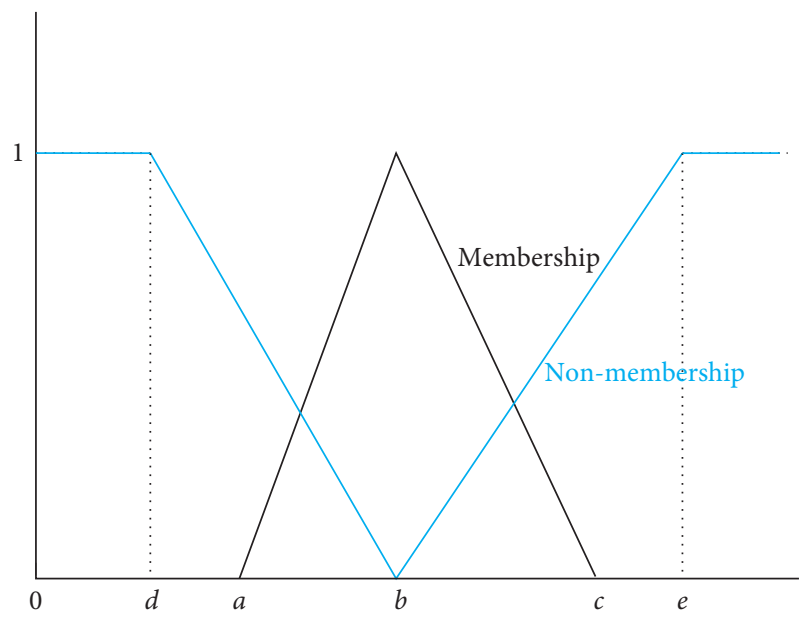

Figure 1: Triangular intuitionistic fuzzy number.

multiplications, and division, are defined by considering two nonnegative triangular intuitionistic fuzzy numbers $\breve{S}^{I}=\left(s_{1}, s_{2}, s_{3} ; s_{1}^{\prime}, s_{2}, s_{3}^{\prime}\right)$ and $\breve{C}^{I}=\left(r_{1}, r_{2}, r_{3} ; r_{1}^{\prime}, r_{2}, r_{3}^{\prime}\right)$. Two triangular intuitionistic fuzzy numbers are equal, $\stackrel{-}{S}^{I}=\stackrel{-}{R}$, if and only if $s_{1}=r_{1}, s_{2}=r_{2}, s_{3}=r_{3}, s_{1}^{\prime}=r_{1}^{\prime}$, and $s_{3}^{\prime}=r_{3}^{\prime}$.

\subsection{Addition}

$$
\begin{aligned}
\stackrel{I}{S} \oplus \breve{R}^{I} & =\left(s_{1}, s_{2}, s_{3} ; s_{1}^{\prime}, s_{2}, s_{3}^{\prime}\right) \oplus\left(r_{1}, r_{2}, r_{3} ; r_{1}^{\prime}, r_{2}, r_{3}^{\prime}\right) \\
& =\left(s_{1}+r_{1}, s_{2}+r_{2}, s_{3}+r_{3} ; s_{1}^{\prime}+r_{1}^{\prime}, s_{2}+r_{2}, s_{3}^{\prime}+r_{3}^{\prime}\right) .
\end{aligned}
$$

\subsection{Subtraction}

$$
\begin{aligned}
\stackrel{I}{S} \ominus \breve{R}^{I} & =\left(s_{1}, s_{2}, s_{3} ; s_{1}^{\prime}, s_{2}, s_{3}^{\prime}\right) \ominus\left(r_{1}, r_{2}, r_{3} ; r_{1}^{\prime}, r_{2}, r_{3}^{\prime}\right), \\
& =\left(s_{1}, s_{2}, s_{3} ; s_{1}^{\prime}, s_{2}, s_{3}^{\prime}\right) \ominus\left(r_{1}, r_{2}, r_{3} ; r_{1}^{\prime}, r_{2}, r_{3}^{\prime}\right) .
\end{aligned}
$$

\subsection{Symmetric Property}

$$
-\left(\breve{S}^{I}\right)=\left(-s_{1},-s_{2},-s_{3} ;-s_{1}^{\prime},-s_{2},-s_{3}^{\prime}\right) .
$$

3.4. Scalar Multiplication. Let $\alpha$ be any scalar; then,

$$
\begin{aligned}
& \alpha\left(\breve{S}^{I}\right)==\left(\alpha s_{1}, \alpha s_{2}, \alpha s_{3} ; \alpha s_{1}^{\prime}, \alpha s_{2}, \alpha s_{3}^{\prime}\right), \alpha \geq 0, \\
& \alpha\left(\breve{S}^{I}\right)=\left(\alpha s_{3}, \alpha s_{2}, \alpha s_{1} ; \alpha s_{3}^{\prime}, \alpha s_{2}, \alpha s s_{1}^{\prime}\right), \alpha<0 .
\end{aligned}
$$

\subsection{Multiplication}

$$
\begin{aligned}
\breve{S}^{I} \otimes \breve{R}^{I} & =\left(s_{1}, s_{2}, s_{3} ; s_{1}^{\prime}, s_{2}, s_{3}^{\prime}\right) \otimes\left(r_{1}, r_{2}, z_{3} ; r_{1}^{\prime}, r_{2}, r_{3}^{\prime}\right) \\
& \cong\left(s_{1} r_{1}, s_{2} r_{2}, s_{3} r_{3} ; s_{1}^{\prime} r_{1}^{\prime}, s_{2} r_{2}, s_{3}^{\prime} r_{3}^{\prime}\right) .
\end{aligned}
$$


Remark 1. If $\breve{S}$ and $\breve{R}$ are not nonnegative triangular fuzzy numbers, then their multiplication will be performed as

$$
\breve{S}^{I} \otimes \breve{R}^{I}=\left(a, b, c ; a^{\prime}, b^{\prime}, c^{\prime}\right),
$$

where

$$
\begin{aligned}
a & =\min \left(s_{1} r_{1}, s_{1} r_{3}, s_{3} r_{1}, s_{3} r_{3}\right), \\
a^{\prime} & =\min \left(s_{1}^{\prime} r_{1}^{\prime}, s_{1}^{\prime} r_{3}^{\prime}, s_{3}^{\prime} r_{1}^{\prime}, s_{3}^{\prime} r_{3}^{\prime}\right), \\
b & =s_{2} r_{2}, \\
b^{\prime} & =s_{2} r_{2}, \\
c & =\max \left(s_{1} r_{1}, s_{1} r_{3}, s_{3} r_{1}, s_{3} r_{3}\right), \\
c^{\prime} & =\max \left(s_{1}^{\prime} r_{1}^{\prime}, s_{1}^{\prime} r_{3}^{\prime}, s_{3}^{\prime} r_{1}^{\prime}, s_{3}^{\prime} r_{3}^{\prime}\right) .
\end{aligned}
$$

\section{Linear Programming Model}

General linear programming [16] is defined as

$$
(\operatorname{Max}) Z(x)=\sum_{i=1}^{p} \sum_{j=1}^{q} c_{i j} x_{i j},
$$

subject to the following constraints:

$$
\sum_{i=1}^{p} \sum_{j=1}^{q} a_{i j} x_{i j}=u_{i}
$$

Condition of nonnegativity is as follows:

$$
x_{\mathrm{ij}} \geq 0 \text { for all } i=1,2, \ldots, p ; j=1,2, \ldots, q,
$$

where $x_{\mathrm{ij}}, c_{\mathrm{ij}}, a_{\mathrm{ij}}$, and $u_{i}$ are the decision variables, coefficients of quantity which we have to maximize or minimize, constraints coefficients, and constants, respectively. This represents the crisp modeling of the problem, but for the most beneficial implementation of this model in our daily life problems, we used its modified form "triangular intuitionistic fuzzy linear programming" which is endowed with the generalized techniques for the absorbtion of fuzziness due to unpredictable and unfortunate scenario.

\section{Triangular Intuitionistic Fuzzy Linear Programming Model}

Triangular intuitionistic fuzzy linear programming enhances the targeted requirements by evaluating the problem specifications meticulously using the generalization of fuzzy logics intuitionistic fuzzy sets. A triangular intuitionistic fuzzy linear programming [25] can be formulated as follows:

$$
(\operatorname{Max}) \breve{Z}^{I}=\sum_{i=1}^{p} \sum_{j=1}^{q} \breve{c}_{i j}^{I} \otimes \breve{x}_{i j}^{I},
$$

subject to the following constraints:

$$
\sum_{i=1}^{p} \sum_{j=1}^{q} \breve{a}_{i j}^{I} \otimes \breve{x}_{i j}^{I}=\breve{u}_{i}^{I}
$$

Condition of nonnegativity is as follows:

$$
\breve{x}_{i j}^{I} \geq 0 \text { for all } i=1,2, \ldots, p ; j=1,2, \ldots, q \text {, }
$$

where the model contains all coefficients, variables, and constants in the form of triangular intuitionistic fuzzy numbers; for example, $\stackrel{-}{c}_{i j}^{I}=\left(c_{i j, 1}, c_{i j, 2}, c_{i j, 3} ; c_{i j, 1}^{\prime}, c_{i j, 2}, c_{i j, 3}^{\prime}\right)$, $\stackrel{-}{a}_{i j}^{I}=\left(a_{i j, 1}, a_{i j, 2}, a_{i j, 3} ; a_{i j, 1}^{\prime}, a_{i j, 2}, a_{i j, 3}^{\prime}\right)$, and $\breve{u}_{i}^{I}=\left(u_{i, 1}, u_{i, 2}\right.$, $\left.u_{i, 3} ; u_{i, 1}^{\prime}, u_{i, 2}, u_{i, 3}^{\prime}\right)$ are triangular intuitionistic fuzzy cost coefficients, triangular intuitionistic fuzzy constraints coefficients, and constants, respectively, with $\breve{x}_{i j}^{I}=\left(x_{i j, 1}\right.$, $\left.x_{i j, 2}, x_{i j, 3} ; x_{i j, 1}^{\prime}, x_{i j, 2}, x_{i j, 3}^{\prime}\right)$ being triangular intuitionistic fuzzy decision variables. Ultimately, $\breve{Z}$ is the maximum triangular intuitionistic fuzzy objective value.

\section{Methodology}

The linear programming for fruit production maximization is developed as

$$
(\operatorname{Max}) \operatorname{FP}_{M}(x)=\sum_{i=1}^{p} \sum_{j=1}^{q} P_{i j} x_{i j},
$$

subject to the following constraints:

$$
\sum_{i=1}^{p} \sum_{j=1}^{q} A_{i j} x_{i j}=v_{i}
$$

Condition of nonnegativity is as follows:

$$
x_{i j} \geq 0 \text { for all } i=1,2, \ldots, p ; j=1,2, \ldots, q \text {, }
$$

where $\mathrm{FP}_{M}$ is maximized fruit production; $x_{i j}$ refers to activities (cutting, pruning, harvesting, thinning, leveling, sales, etc.); $P_{i j}$ indicates objective coefficients (market prices of variables, product profit, etc.); $A_{i j}$ denotes constraints coefficients (utilized resources and capital per unit of fruit production); and $v_{i}$ is the total available amount/units/ volume of supplies per hector.

Generally defined constraints for major fruit production are further written as follows:

total land availability constraints: $\sum_{i=1}^{h} G_{i}^{l} \leq \mathrm{TL}$, maximum sowing area constraints: $G_{1}^{l} \leq \mathrm{TL}^{G}$,

$: G_{2}^{l} \leq \mathrm{TL}^{A} \mathbb{Z}$,

$: G_{3}^{l} \leq \mathrm{TL}^{C}$,

$: G_{4}^{l} \leq \mathrm{TL}^{\mathrm{AL}}$,

: $G_{5}^{l} \leq \mathrm{TL}^{\mathrm{PL}}$,

availability of labor units constraints: $\sum H_{i} R_{i} \leq \mathrm{TH}_{i}$,

balanced fertilizers input constraints: $\sum F_{i} R_{i}=0$,

pesticide input constraints: $\sum S_{i} R_{i}=0$,

cost constraints: $\sum B_{i} R_{i}=0$,

average yield constraints: $\sum Y_{i} R_{i}-M_{i}=0$,

where $h$ is the total number of fruit crops, TL is the total cultivated land, $G_{i}^{l}$ is the total available area for each fruit, 
$\mathrm{TL}^{G}$ is the total area for grapes, $\mathrm{TL}^{A}$ is the total area for apples, $\mathrm{TL}^{C}$ is the total area for cherry, $\mathrm{TL}^{\mathrm{AL}}$ is the total area for almond, $\mathrm{TL}^{\mathrm{PL}}$ is the total area for plum, $\mathrm{TH}_{i}$ is the total available hours or man-days for labor, $R_{i}$ is the area for each fruit crop, $H_{i}$ is the required working hours or man-days for each $i$ th crop, $F_{i}$ represents the required amount of fertilizer per hector, $S_{i}$ represents the required amount of pesticide per hector, $B_{i}$ is the total cost per hector, $Y_{i}$ is the amount of yields in $\mathrm{kg}$ per hector, and $M_{i}$ is the market selling price of yield per $\mathrm{kg}$.

Then, we need much more precision regarding data and situation analysis because of changing factors and circumstances in our universe. The world we are living in is not like before; it is constantly changing, which makes it more challenging for us to change ourselves and our methods according to that change. The simple linear programming is not enough for our environment changes like climate changes, economic downfall, fluctuation of prices and demand, unsuitability of resources, pest and diseases, governmental policies, international trade agreements, topography, and political and social factors. We made a conscious effort regarding this issue especially for the hyperarid zones of Pakistan to improve our food security and GDP. Here, a triangular fuzzy linear programming is formulated according to the present situation analysis of fruit production of Pakistan for improvement.

The triangular intuitionistic fuzzy linear programming for fruit production maximization is developed as

$$
(\operatorname{Max}) \breve{\mathrm{FP}}_{M}^{I}=\sum_{i=1}^{p} \sum_{j=1}^{q} \breve{P}_{\mathrm{ij}}^{I} \otimes \breve{x}_{\mathrm{ij}}^{I},
$$

subject to the following constraints:

$$
\sum_{i=1}^{p} \sum_{j=1}^{q} \breve{K}_{\mathrm{ij}}^{I} \otimes \breve{x}_{\mathrm{ij}}^{I}=\breve{v}_{i}^{I} .
$$

Condition of nonnegativity is as follows:

$$
\breve{x}_{\mathrm{ij}}^{I} \geq 0 \text { for all } i=1,2, \ldots, p ; j=1,2, \ldots, q,
$$

where $\widetilde{F P}_{M}$ is the triangular intuitionistic fuzzy maximized fruit production; $\breve{x}_{\mathrm{ij}}^{I}$ refers to the triangular intuitionistic fuzzy activities (cutting, pruning, harvesting, thinning, leveling, sales, etc.); $\stackrel{\smile}{P}_{\mathrm{ij}}^{I}$ indicates the objective triangular intuitionistic fuzzy coefficients (market prices of variables, product profit, etc.); $\breve{K}_{\mathrm{ij}}^{I}$ represents the triangular intuitionistic fuzzy constraints coefficients (utilized resources and capital per unit of fruit production); and $\breve{v}_{i}^{I}$ is the total available triangular intuitionistic fuzzy amount/units/volume of supplies per hector.

The objective function and constraints equations will be written as

$$
\begin{aligned}
(\mathrm{Max}) \breve{\mathrm{FP}}_{M}^{I}= & \sum_{i=1}^{p} \sum_{j=1}^{q}\left(P_{\mathrm{ij}, 1}, P_{\mathrm{ij}, 2}, P_{\mathrm{ij}, 3} ; P_{\mathrm{ij}, 1}^{\prime}, P_{\mathrm{ij}, 2}, P_{\mathrm{ij}, 3}^{\prime}\right) \otimes\left(x_{\mathrm{ij}, 1}, x_{\mathrm{ij}, 2}, x_{\mathrm{ij}, 3} ; x_{\mathrm{ij}, 1}^{\prime}, x_{\mathrm{ij}, 2}, x_{\mathrm{ij}, 3}^{\prime}\right) \\
& \cdot \sum_{i=1}^{p} \sum_{j=1}^{q}\left(K_{\mathrm{ij}, 1}, K_{\mathrm{ij}, 2}, K_{\mathrm{ij}, 3} ; K_{\mathrm{ij}, 1}^{\prime}, K_{\mathrm{ij}, 2}, K_{\mathrm{ij}, 3}^{\prime}\right) \otimes\left(x_{\mathrm{ij}, 1}, x_{\mathrm{ij}, 2}, x_{\mathrm{ij}, 3} ; x_{\mathrm{ij}, 1}^{\prime}, x_{\mathrm{ij}, 2}, x_{\mathrm{ij}, 3}^{\prime}\right)=\left(u_{i, 1}, u_{i, 2}, u_{i, 3} ; u_{i, 1}^{\prime}, u_{i, 2}, u_{i, 3}^{\prime}\right) \\
& \cdot\left(x_{\mathrm{ij}, 1}, x_{\mathrm{ij}, 2}, x_{\mathrm{ij}, 3} ; x_{\mathrm{ij}, 1}^{\prime}, x_{\mathrm{ij}, 2}, x_{\mathrm{ij}, 3}^{\prime}\right) \geqslant 0
\end{aligned}
$$

By using the operations of triangular fuzzy numbers,

$$
\begin{aligned}
&(\max ) \breve{F P}_{M}^{I}= \sum_{i=1}^{p} \sum_{j=1}^{q}\left(P_{i j, 1} x_{i j, 1}, P_{i j, 2} x_{i j, 2}, P_{i j, 3} x_{i j, 3} ; P_{i j, 1}^{\prime} x_{i j, 1}{ }^{\prime}, P_{i j, 2} x_{i j, 2}, P_{i j, 3}{ }^{\prime} x_{i j, 3}{ }^{\prime}\right) \\
& \cdot \sum_{i=1}^{p} \sum_{j=1}^{q}\left(K_{i j, 1} x_{i j, 1}, K_{i j, 2} x_{i j, 2}, K_{i j, 3} x_{i j, 3} ; K_{i j, 1}^{\prime} x_{i j, 1}^{\prime}, K_{i j, 2} x_{i j, 2}, K_{i j, 3}{ }^{\prime} x_{i j, 3}^{\prime}\right)=\left(u_{i, 1}, u_{i, 2}, u_{i, 3} ; u_{i, 1}^{\prime}, u_{i, 2}, u_{i, 3}^{\prime}\right) \\
& x_{i j, 3}{ }^{\prime} \geq 0, x_{i j, 3}-x_{i j, 3}{ }^{\prime} \geq 0, x_{i j, 2}-x_{i j, 3} \geq 0, x_{i j, 1}-x_{i j, 2} \geq 0, x_{i j, 1}^{\prime}-x_{i j, 1} \geq 0
\end{aligned}
$$


Further simplification was carried out using accuracy function on the triangular intuitionistic fuzzy objective function.

$$
\begin{aligned}
& \mathbf{W} \max \left(\sum_{i=1}^{p} \sum_{j=1}^{q} P_{\mathrm{ij}, 1} x_{i j, 1}, \sum_{i=1}^{p} \sum_{j=1}^{q} P_{\mathrm{ij}, 2} x_{\mathrm{ij}, 2}, \sum_{i=1}^{p} \sum_{j=1}^{q} P_{\mathrm{ij}, 3} x_{\mathrm{ij}, 3} ; \sum_{i=1}^{p} \sum_{j=1}^{q} P_{\mathrm{ij}, 1}^{\prime} x_{\mathrm{ij}, 1}^{\prime},\right. \\
& \left.\quad \sum_{i=1}^{p} \sum_{j=1}^{q} P_{\mathrm{ij}, 2} x_{\mathrm{ij}, 2}, \sum_{i=1}^{p} \sum_{j=1}^{q} P_{\mathrm{ij}, 3}^{\prime} x_{\mathrm{ij}, 3}^{\prime}\right) \\
& =\frac{1}{8}\left(\sum_{i=1}^{p} \sum_{j=1}^{q} P_{\mathrm{ij}, 1} x_{\mathrm{ij}, 1}+2 \sum_{i=1}^{p} \sum_{j=1}^{q} P_{\mathrm{ij}, 2} x_{\mathrm{ij}, 2}+\sum_{i=1}^{p} \sum_{j=1}^{q} P_{\mathrm{ij}, 3} x_{\mathrm{ij}, 3}\right) \\
& +\frac{1}{8}\left(\sum_{i=1}^{p} \sum_{j=1}^{q} P_{\mathrm{ij}, 1} x_{\mathrm{ij}, 1}^{\prime}+2 \sum_{i=1}^{p} \sum_{j=1}^{q} P_{\mathrm{ij}, 2} x_{\mathrm{ij}, 2}+\sum_{i=1}^{p} \sum_{j=1}^{q} P_{\mathrm{ij}, 3}^{\prime} x_{\mathrm{ij}, 3}^{\prime}\right) .
\end{aligned}
$$

Ultimately, triangular intuitionistic fuzzy objective function is transmuted into linear objective function by accuracy function, and regarding that reference, the constraints are thoroughly modified into

$$
\begin{aligned}
& \left(\sum_{i=1}^{p} \sum_{j=1}^{q} K_{\mathrm{ij}, 1} x_{\mathrm{ij}, 1}, \sum_{i=1}^{p} \sum_{j=1}^{q} K_{\mathrm{ij}, 2} x_{\mathrm{ij}, 2}, \sum_{i=1}^{p} \sum_{j=1}^{q} K_{\mathrm{ij}, 3} x_{\mathrm{ij}, 3} ; \sum_{i=1}^{p} \sum_{j=1}^{q} K_{\mathrm{ij}, 1}^{\prime} x_{\mathrm{ij}, 1}^{\prime}, \sum_{i=1}^{p} \sum_{j=1}^{q} K_{\mathrm{ij}, 2} x_{\mathrm{ij}, 2}, \sum_{i=1}^{p} \sum_{j=1}^{q} K_{\mathrm{ij}, 3}^{\prime} x_{\mathrm{ij}, 3}^{\prime}\right) \\
& =\left(u_{i, 1}, u_{i, 2}, u_{i, 3} ; u_{i, 1}^{\prime}, u_{i, 2}, u_{i, 3}^{\prime}\right) .
\end{aligned}
$$

Using the equality condition of triangular intuitionistic fuzzy number, we have

$$
\begin{aligned}
& \sum_{i=1}^{p} \sum_{j=1}^{q} K_{\mathrm{ij}, 1} x_{\mathrm{ij}, 1}=u_{i, 1}, \\
& \sum_{i=1}^{p} \sum_{j=1}^{q} K_{\mathrm{ij}, 2} x_{\mathrm{ij}, 2}=u_{i, 2}, \\
& \sum_{i=1}^{p} \sum_{j=1}^{q} K_{\mathrm{ij}, 3} x_{\mathrm{ij}, 3}=u_{i, 3}, \\
& \sum_{i=1}^{p} \sum_{j=1}^{q} K_{\mathrm{ij}, 1}{ }^{\prime} x_{\mathrm{ij}, 1}{ }^{\prime}=u_{i, 1}{ }^{\prime}, \\
& \sum_{i=1}^{p} \sum_{j=1}^{q} K_{\mathrm{ij}, 2} x_{\mathrm{ij}, 2}=u_{i, 2}, \\
& \sum_{i=1}^{p} \sum_{j=1}^{q} K_{\mathrm{ij}, 3}{ }^{\prime} x_{\mathrm{ij}, 3}{ }^{\prime}=u_{i, 3}{ }^{\prime} .
\end{aligned}
$$

Now, the model is converted into simple linear problem which can be easily solved through LP algorithm or Excel Solver. Then, we get the values of unknowns (decision variables) that are substituted into the triangular intuitionistic fuzzy objective function to get the maximized result in the form of triangular intuitionistic fuzzy number.

\section{Application}

The provinces of Punjab and Baluchistan produce abundant amount of fruit where Baluchistan lies in the arid regions of Pakistan. Baluchistan is the largest province on the basis of area occupying 347,190 square kilometres and located in southwest direction. The climatic conditions of Baluchistan region are characterized by very cold winter and very hot summer with maximum of $50^{\circ} \mathrm{C}$ to $53^{\circ} \mathrm{C}$ [31]. Moreover, strong windstorms and temperature make the area very hot arid zone, which is referred to as hyperarid zone. Baluchistan contributes nearly $4.9 \%$ to GDP which is far less than other provinces. Recently, water availability for the expansion of sustainable agricultural land is achieved by making Mirani Dam on the Dasht River which irrigates $35,000 \mathrm{~km}^{2}$ of area [32]. For practical application of our formulated models, data for fruit production is collected from Baluchistan and is arranged in tabular form for easy further use. 


\section{Mathematical Model Formulation}

The practical formulation of the model is carried out through the application of the above statistics that are specifically gathered from the Baluchistan province based on the data given in Tables 1-3.

Objective function is as follows:

$$
\operatorname{Max} Z_{\mathrm{FP}}=-110 x_{5}+X_{7}+160 x_{9}+120 x_{10}+150 x_{11}+150 x_{12}+200 x_{13} \text {, }
$$

subject to the following constraints:

$$
\begin{aligned}
x_{1}+x_{2}+x_{3}+x_{4}+x_{5} & =120, \\
x_{1} & \leq 30, \\
x_{2} & \leq 30, \\
x_{3}+x_{4}+x_{5} & \leq 60, \\
-300 x_{1}-250 x_{2}-200 x_{3}-210 x_{4}-230 x_{5}+x_{6} & =0, \\
3000 x_{1}+2850 x_{2}+2900 x_{3}+3100 x_{4}+3050 x_{5}-x_{7} & =0, \\
-6.1 x_{1}-3.5 x_{2}-4.5 x_{3}-3.2 x_{4}-3.5 x_{5}+x_{8} & \leq 20.5, \\
13700 x_{1}-x_{9} & =0, \\
17100 x_{1}-x_{10} & =0, \\
25000 x_{1}-x_{11} & =0, \\
81600 x_{1}-x_{12} & =0, \\
52800 x_{1}-x_{13} & =0, \\
52800 x_{1}-x_{13} & =0 .
\end{aligned}
$$

In this model, we used fertilizers, all types of cost, available labor hours, and average fruit yield as constraints to find the optimal fruit production. After the above developments, we used Excel Solver for the maximum yield which gives objective value $Z_{\mathrm{FP}}=858880500 \mathrm{~kg}$. Afterwards, fuzzy modification of model is carried out to figure out more optimal way of modeling the existing methodology. The triangular fuzzy intuitionistic linear programming is given as follows.

Intuitionistic fuzzy objective function is as follows:

$$
\begin{aligned}
(\operatorname{Max}) \breve{Z}_{\mathrm{FP}}^{I}= & \left(-(120,110,100 ; 130,110,90) \otimes \breve{x}_{6}^{I}\right)+\left((1.3,1,0.7 ; 1.6,1,0.4) \otimes \breve{x}_{7}^{I}\right)+\left((180,160,140 ; 200,160,120) \otimes \breve{x}_{9}^{I}\right) \\
& +\left((140,120,100 ; 160,120,180) \otimes \breve{x}_{10}^{I}\right)+\left((175,150,125 ; 200,150,100) \otimes \breve{x}_{11}^{I}\right) \\
& +\left((160,150,140 ; 170,150,130) \otimes \breve{x}_{12}^{I}\right)+\left((220,200,180 ; 240,200,160) \otimes \breve{x}_{13}^{I}\right),
\end{aligned}
$$


TABLE 1: Orchard area statistics.

\begin{tabular}{lccc}
\hline Specifications & Occupied area (ha) & Percentage of average cultivated land (\%) & Number of trees $(\backslash$ ha) \\
\hline Apple & 30 & 25 & 900 \\
Grapes & 30 & 25 & 1000 \\
Apricot & 20 & 16.66 & 455 \\
Peach & 20 & 16.66 & 450 \\
Plum & 20 & 16.66 & 430 \\
Total & 120 & 100 & 3235 \\
\hline
\end{tabular}

TABLE 2: Orchard production statistics.

\begin{tabular}{lcc}
\hline Specifications & Yield (kg\ha) & Price $(\mathrm{Rs} \backslash \mathrm{kg})$ \\
\hline Apple & 13700 & 160 \\
Grapes & 17100 & 120 \\
Apricot & 25000 & 150 \\
Peach & 81600 & 150 \\
Plum & 52800 & 200 \\
\hline
\end{tabular}

subject to the following intuitionistic fuzzy constraints:
TABle 3: Material consumption statistics.

\begin{tabular}{lccc}
\hline \multicolumn{4}{c}{ Available units (kg, hrs, Rs $\backslash$ ha) } \\
Specifications & Fertilizers (kg\ha) & Cost (Rs $\backslash$ ha) & Labor (hrs $\backslash$ ha) \\
\hline Apple & 300 & 3000 & 6.1 \\
Grapes & 250 & 2850 & 3.5 \\
Apricot & 200 & 2900 & 4.5 \\
Peach & 210 & 3100 & 3.2 \\
Plum & 230 & 3050 & 3.5
\end{tabular}

Price of the fertilizer is Rs $110 / \mathrm{kg}$.

$(1.4,1,0.6 ; 1.8,1,0.2) \breve{x}_{1}^{I}+(1.3,1,0.7 ; 1.6,1,0.4) \breve{x}_{2}^{I}+(1.2,1,0.8 ; 1.4,1,0.6) \breve{x}_{3}^{I}+(1.1,1,0.9 ; 1.2,1,0.8)$

$\cdot \breve{x}_{4}^{I}+(1.4,1,0.6 ; 1.8,1,0.2) \breve{x}_{5}^{I}=(125,120,115 ; 130,120,110)$,

$\cdot(1.3,1,0.7 ; 1.6,1,0.4) \breve{x}_{1}^{I} \leq(35,30,25 ; 40,30,20)$,

$\cdot(1.3,1,0.7 ; 1.6,1,0.4) \breve{x}_{2}^{I} \leq(35,30,25 ; 40,30,20)$,

$\cdot(1.4,1,0.6 ; 1.8,1,0.2) \breve{x}_{3}^{I}+(1.2,1,0.8 ; 1.4,1,0.6) \breve{x}_{4}^{I}+(1.1,1,0.9 ; 1.2,1,0.8) \breve{x}_{5}^{I} \leq(65,60,55 ; 70,60,50)$,

$-(310,300,290 ; 320,300,280) \breve{x}_{1}^{I}-(260,250240 ; 270,250,230) \breve{x}_{2}^{I}-(205,200,195 ; 210,200,190) \breve{x}_{3}^{I}-$

$\cdot(220,210,200 ; 230,210,190) \breve{x}_{4}^{I}-(240,230,220 ; 250,230,210) \breve{x}_{5}^{I}+(1.4,1,0.6 ; 1.8,1,0.2) \breve{x}_{6}^{I}=\breve{0}^{I}$,

$\cdot(3050,3000,2950 ; 3100,3000,2900) \breve{x}_{1}^{I}+(2900,2850,2800 ; 2950,2850,2750) \breve{x}_{2}^{I}+$

$\cdot(2925,2900,2875 ; 2950,2900,2850) \breve{x}_{3}^{I}+(3200,3100,3000 ; 3300,3100,2900) \breve{x}_{4}^{I}+$

$\cdot(3100,3050,3000 ; 3150,3050,2950) \breve{x}_{5}^{I}-(1.4,1,0.6 ; 1.8,1,0.2) \breve{x}_{7}^{I}=\breve{0}^{I}$,

$-(6.4,6.1,5.8 ; 6.7,6.1,5.5) \breve{x}_{1}^{I}-(4,3.5,3 ; 4.4,3.5,2.5) \breve{x}_{2}^{I}-(4.8,4.5,4.2 ; 5.1,4.5,3.9) \breve{x}_{3}^{I}-(3.4,3.2,3$;

. 3.6, 3.2, 2.8) $\breve{x}_{4}^{I}-(3.75,3.5,3.25 ; 4,3.5,3) \breve{x}_{5}^{I}+(1.4,1,0.6 ; 1.8,1,0.2) \breve{x}_{8}^{I} \leq(21,20.5,20 ; 21.5,20.5,19.5)$,

$\cdot(13800,13700,13600 ; 13900,13700,13500) \breve{x}_{1}^{I}-(1.4,1,0.6 ; 1.8,1,0.2) \breve{x}_{9}^{I}=\breve{0}^{I}$,

. $(17200,17100,17000 ; 17300,17100,16900) \breve{x}_{2}^{I}-(1.4,1,0.6 ; 1.8,1,0.2) \breve{x}_{10}^{I}=\breve{0}^{I}$,

. $(25100,25000,24900 ; 25200,2500,24800) \breve{x}_{3}^{I}-(1.4,1,0.6 ; 1.8,1,0.2) \breve{x}_{11}^{1}=\breve{0}^{I}$,

$\cdot(81700,81600,81500 ; 81800,81600,81400) \breve{x}_{4}^{I}-(1.4,1,0.6 ; 1.8,1,0.2) \breve{x}_{12}^{I}=\breve{0}^{I}$,

. $(52850,52800,52750 ; 52900,52800,52700) \breve{x}_{5}^{I}-(1.4,1,0.6 ; 1.8,1,0.2) \breve{x}_{13}^{I}=\breve{0}$.

This is the mathematical formulation of triangular intuitionistic fuzzy linear programming in which all the decision variables and the regarding coefficients are triangular intuitionistic fuzzy numbers. As stated above, we cannot directly solve this model. Ultimately, we convert this model into crisp linear programming by using the accuracy 
function and arithmetic operations of triangular intuitionistic fuzzy numbers accordingly.

$\left(\left(-(120,110,100 ; 130,110,90) \otimes \breve{x}_{6}^{I}\right)+\left((1.3,1,0.7 ; 1.6,1,0.4) \otimes \breve{x}_{7}^{I}\right)+((180,160,140 ; 200,160,120)\right.$ $\left.\otimes \vec{x}_{9}^{I}\right)+\left((140,120,100 ; 160,120,180) \otimes \vec{x}_{10}^{I}\right)+\left((175,150,125 ; 200,150,100) \otimes \vec{x}_{11}^{I}\right)+((160,150,140 ;$ $\left.\left.170,150,130) \otimes \breve{x}_{12}^{I}\right)+\left((220,200,180 ; 240,200,160) \otimes \breve{x}_{13}^{I}\right)\right)$,

$$
\begin{aligned}
& \text { (Max) } \breve{Z}_{\mathrm{FP}}^{I}=\frac{1}{8}\left\{-120 x_{6,1}+1.3 x_{7,1}+180 x_{9,1}-140 x_{10,1}-175 x_{11,1}+160 x_{12,1}+220 x_{13,1}\right\}+\frac{4}{8}\left\{-110 x_{6,2}\right. \\
& \left.+1 x_{7,2}+160 x_{9,2}-120 x_{10,2}-150 x_{11,2}+150 x_{12,2}+200 x_{13,2}\right\}+\frac{1}{8}\left\{-100 x_{6,3}+0.7 x_{7,3}\right. \\
& \left.+140 x_{9,3}-100 x_{10,3}-125 x_{11,3}+140 x_{12,3}+180 x_{13,3}\right\}+\frac{1}{8}\left\{-130 x_{6,1}^{\prime}+1.6 x_{7,4}^{\prime}+200 x_{9,4}^{\prime}\right. \\
& \left.-160 x_{10,1}^{\prime}-200 x_{11,1}^{\prime}+170 x_{12,1}^{\prime}+240 x_{13,1}^{\prime}\right\}+\frac{1}{8}\left\{-90 x_{6,3}^{\prime}+0.4 x_{7,3}^{\prime}+120 x_{9,3}^{\prime}-180 x_{10,3}^{\prime}\right. \\
& \left.-100 x_{11,3}^{\prime}+130 x_{12,3}^{\prime}+160 x_{13,3}^{\prime}\right\} .
\end{aligned}
$$

Along with the linear constraints simplification, which is carried out using the arithmetic operations of multiplication and equality of triangular intuitionistic fuzzy numbers according to the methodology, we have the crisp LP model which is simply solved through Excel Solver to find the values of decision variables. The values of decision variables obtained are

$$
\begin{aligned}
& \breve{x}_{1}^{I}=(21.72619048,30,35.7142871 ; 16.666666667,30,50) \text {, } \\
& \breve{x}_{2}^{I}=(26.92307692,30,35.71428571 ; 25,30,50) \text {, } \\
& \breve{x}_{3}^{I}=(0,0,53.57142857 ; 0,0,40) \text {, } \\
& \breve{x}_{4}^{I}=(54.16666667,60,28.57142857 ; 50,60,70) \text {, } \\
& \breve{x}_{5}^{I}=(0,0,0 ; 0,0,0) \text {, } \\
& \breve{x}_{6}^{I}=(18322.70408,29100,58482.14286 ; 13101.85185,29100,232000) \text {, } \\
& \breve{x}_{7}^{I}=(226910.8124,361500,741815.4762 ; 161342.5926,361500,2997500) \text {, } \\
& \breve{x}_{8}^{I}=(0,0,0 ; 0,0,0) \text {, } \\
& \breve{x}_{9}^{I}=(214158.1633,411000,809523.8095 ; 128703.7037,411000,3375000) \text {, } \\
& \breve{x}_{10}^{I}=(330769.2308,513000,1011904.762 ; 240277.7778,513000,4225000) \text {, } \\
& \breve{x}_{11}^{I}=(0,0,2223214.286 ; 0,0,4960000) \text {, } \\
& \breve{x}_{12}^{I}=(3161011.905,4896000,3880952.381 ; 2272222.222,4896000,28490000) \text {, } \\
& \breve{x}_{13}^{I}=(0,0,0 ; 0,0,0) \text {. }
\end{aligned}
$$

The triangular intuitionistic fuzzy objective value is obtained by putting the values of decision variables
$\breve{x}_{1}^{I}, \breve{x}_{2}, \breve{x}_{3}, \breve{x}_{4}^{I}, \breve{x}_{5}^{I} \ldots \breve{x}_{13}^{I}$ into the triangular intuitionistic fuzzy objective function as follows:

$$
\breve{Z}_{\mathrm{FP}}^{I}=(588714344,859026000,1042552710 ; 449017835.6,859026000,5345519000),
$$




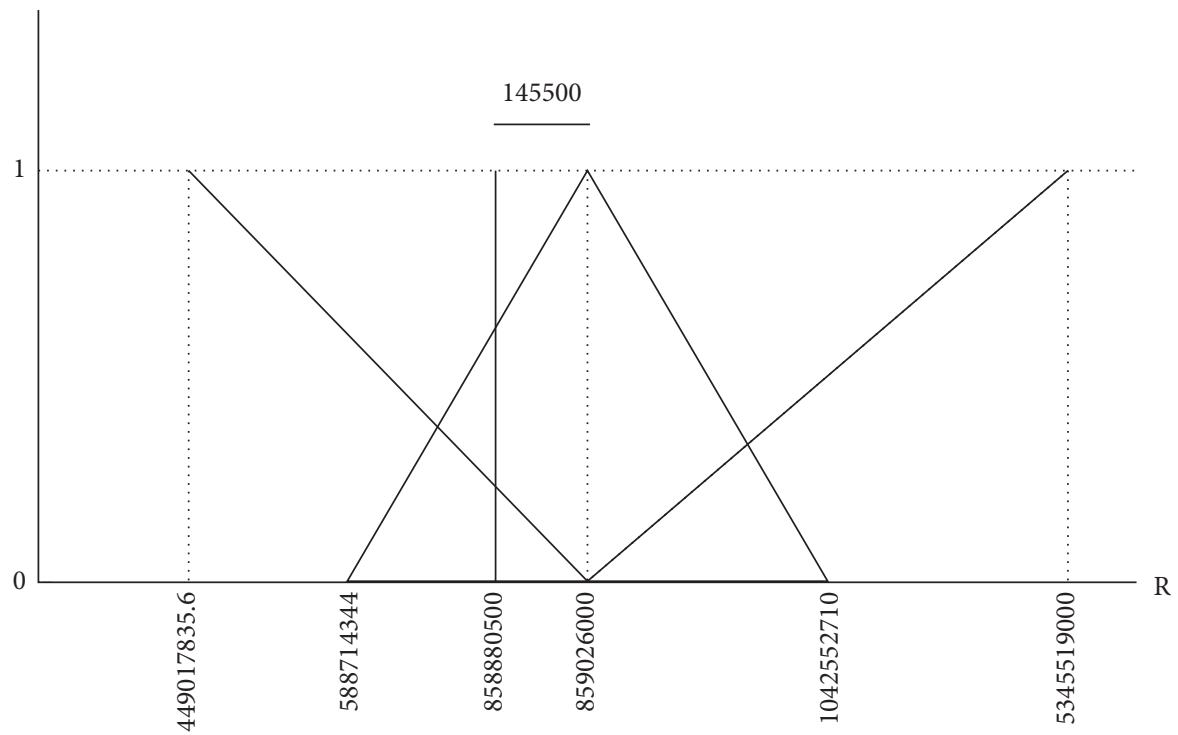

FIGURE 2: Graphical comparison of optimal solution.

TABle 4: Sensitivity report (variables).

\begin{tabular}{|c|c|c|c|c|c|c|c|c|c|}
\hline $\begin{array}{l}\text { Variable } \\
\text { name }\end{array}$ & Final value & $\begin{array}{l}\text { Objective } \\
\text { coefficient }\end{array}$ & $\begin{array}{c}\text { Allowable } \\
\text { increase }\end{array}$ & $\begin{array}{c}\text { Allowable } \\
\text { decrease }\end{array}$ & $\begin{array}{c}\text { Variable } \\
\text { name }\end{array}$ & Final value & $\begin{array}{l}\text { Objective } \\
\text { coefficient }\end{array}$ & $\begin{array}{c}\text { Allowable } \\
\text { increase }\end{array}$ & $\begin{array}{c}\text { Allowable } \\
\text { decrease }\end{array}$ \\
\hline$x_{1,1}$ & 21.72619048 & 0 & 10082.65797 & 333727.8781 & $x_{7,1}^{\prime}$ & 161342.5926 & 0.2 & $1 E+30$ & 50.32943262 \\
\hline$x_{1,2}$ & 30 & 0 & $1.00 E+30$ & 67325 & $x_{7,3}^{\prime \prime 1}$ & 2997500 & 0.05 & 264.5900754 & 157.5387006 \\
\hline$x_{1,3}$ & 35.71428571 & 0 & $1 E+30$ & 5840117.708 & $x_{8,1}$ & 0 & 0 & 0 & $1 E+30$ \\
\hline$x_{1,1}^{\prime \prime, ~}$ & 16.66666667 & 0 & 23365.45139 & 65707.87037 & $x_{8,2}$ & 0 & 0 & 0 & $1 E+30$ \\
\hline$x_{1,3}^{\prime}$ & 50 & 0 & $1 E+30$ & 1394217.5 & $x_{8,3}^{, 2}$ & 0 & 0 & 0 & $1 E+30$ \\
\hline$x_{2,1}$ & 26.92307692 & 0 & $1 E+30$ & 9362468112 & $x_{8,1}^{\prime, j}$ & 0 & 0 & 0 & $1 E+30$ \\
\hline$x_{2,2}^{2,1}$ & 30 & 0 & 67325 & $1 E+30$ & $x_{8,3}^{\prime, 1}$ & 0 & 0 & 0 & $1 E+30$ \\
\hline$x_{2,3}^{2,2}$ & 35.71428571 & 0 & $1 E+30$ & 6706814.583 & $x_{9,1}$ & 214158.1633 & 22.5 & 1.022878344 & 33.8564514 \\
\hline$x_{2,1}^{\prime \prime \prime}$ & 25 & 0 & $1 E+30$ & 20769.29012 & $x_{9,2}^{, 1}$ & 411000 & 80 & $1 E+30$ & 4.914233577 \\
\hline$x_{2,3}^{\prime \prime 2}$ & 50 & 0 & $1 E+30$ & 1626235 & $x_{9,3}$ & 809523.8095 & 17.5 & $1 E+30$ & 257.6522518 \\
\hline$x_{3,1}$ & 0 & 0 & 955994.5206 & $7.45517 E+21$ & $x_{9,1}^{\prime \prime}$ & 128703.7037 & 25 & 3.025741906 & 8.508932854 \\
\hline$x_{3,2}$ & 0 & 0 & 4244550 & $2.29518 E+22$ & $x_{9,3}^{\prime \prime}$ & 3375000 & 15 & $1 E+30$ & 20.65507407 \\
\hline$x_{3,3}^{, 2}$ & 53.57142857 & 0 & 1197645.461 & $1 E+30$ & $x_{10,1}$ & 330769.2308 & 17.5 & $1 E+30$ & 0.762061358 \\
\hline$x_{3,1}^{\prime, 0}$ & $7.105 E-15$ & 0 & 875857.0547 & $1.16921 E+20$ & $\begin{array}{l}10,1 \\
x_{10,2}\end{array}$ & 513000 & 60 & 3.937134503 & $1 E+30$ \\
\hline$x_{3,3}^{\prime, 1}$ & 40 & 0 & 1355195.833 & $1 E+30$ & $x_{10,3}$ & 1011904.762 & 12.5 & $1 E+30$ & 236.7111029 \\
\hline$x_{4,1}$ & 54.16666667 & 0 & $6.08437 E+19$ & 101852.0147 & $x_{10,1}^{\prime}$ & 240277.7778 & 20 & $1 E+30$ & 2.160966602 \\
\hline$x_{4,2}$ & 60 & 0 & $1 E+30$ & 841125 & $x_{10,3}^{\prime \prime, 1}$ & 4225000 & 10 & $1 E+30$ & 19.24538462 \\
\hline$x_{4,3}$ & 28.57142857 & 0 & $1 E+30$ & 1233965.205 & $x_{11,1}$ & 0 & 21.875 & 53.32240354 & $1 E+30$ \\
\hline$x_{4,1}^{\prime \prime, ~}$ & 50 & 0 & $1 E+30$ & 32853.93519 & $x_{11,2}$ & 0 & 75 & 169.782 & $1 E+30$ \\
\hline$x_{4,3}^{\prime, 1}$ & 70 & 0 & $1 E+30$ & 2393337.5 & $x_{11,3}^{11,2}$ & 2223214.286 & 15.625 & 28.85892678 & $1 E+30$ \\
\hline$x_{5,1}^{4,3}$ & 0 & 0 & 9364.34684 & $1 E+30$ & $x_{11,1}^{\prime 1,0}$ & 0 & 25 & 62.56121819 & $1 E+30$ \\
\hline$x_{5,2}^{, 1}$ & 0 & 0 & 841125 & $1 E+30$ & $x_{11,3}^{\prime 1,1}$ & 4960000 & 12.5 & 10.92899866 & $1 E+30$ \\
\hline$x_{5,3}$ & 0 & 0 & 4442274.739 & $1 E+30$ & $x_{12,1}$ & 3161011.905 & 20 & $1.04261 E+15$ & 1.745322162 \\
\hline$x_{5,1}^{\prime \prime \prime}$ & 0 & 0 & 28160.51587 & $1 E+30$ & $x_{12,2}$ & 4896000 & 75 & $1 E+30$ & 10.30790441 \\
\hline$x_{5,3}^{\prime, 1}$ & $3.552 E-15$ & 0 & 5265342.5 & $1 E+30$ & $x_{12,3}$ & 3880952.381 & 17.5 & $1 E+30$ & 9.08440642 \\
\hline$x_{6,1}^{3,0}$ & 18322.70408 & -15 & 470.5240384 & 2701.020218 & $x_{12,1}^{1,2}$ & 2272222.222 & 21.25 & $1 E+30$ & 0.722947229 \\
\hline$x_{6,2}$ & 29100 & -55 & 42056.25 & 1346.5 & $x_{12,3}^{\prime}$ & 28490000 & 16.25 & $1 E+30$ & 5.880436118 \\
\hline$x_{6,3}$ & 58482.1486 & -12.5 & 18573.97104 & 47352.30574 & $x_{13,1}$. & 0 & 27.5 & 2.473227731 & $1 E+30$ \\
\hline$x_{6,1}^{\prime}$ & 13101.85185 & -16.25 & 2588.173077 & 601.3940678 & $x_{13,2}$ & 0 & 100 & 15.93039773 & $1 E+30$ \\
\hline$x_{6,3}^{\prime}$ & 232000 & -11.25 & 3682.057692 & 1366.879902 & $\begin{array}{l}13,2 \\
x_{13,3}\end{array}$ & 0 & 22.5 & 50.52824348 & $1 E+30$ \\
\hline$x_{7,1}$ & 226910.8124 & 0.1625 & $1.00 E+30$ & 190.3709959 & $x_{13,1}^{\prime}$ & 0 & 30 & 0.958202809 & $1 E+30$ \\
\hline$x_{7,2}^{, 1}$ & 361500 & 0.5 & $1 E+30$ & 448.8333333 & $x_{13,3}^{\prime}$ & 0 & 20 & 19.98232448 & $1 E+30$ \\
\hline$x_{7,3}$ & 741815.4762 & 0.0875 & 1579.475463 & $1 E+30$ & & & & & \\
\hline
\end{tabular}


TABLE 5: Sensitivity report (constraints).

\begin{tabular}{|c|c|c|c|c|c|}
\hline Constraints (LHS) & Final value & Shadow price & Constraints (RHS) & Allowable increase & Allowable decrease \\
\hline Total land 1 LHS & 125 & 156298.7883 & 125 & 7.275641026 & 30.41666667 \\
\hline Total land 2 LHS & 120 & 1013675 & 120 & 0 & 30 \\
\hline Total land 3 LHS & 115 & -9081770.833 & 115 & 4.761904762 & 6.696428571 \\
\hline Total land 4 LHS & 130 & 105839.5062 & 130 & 15 & 30 \\
\hline Total land 5 LHS & 110 & -1983712.5 & 110 & 70 & 13.33333333 \\
\hline Land for apple 1 LHS & 28.24404762 & 0 & 35 & $1 E+30$ & 6.755952381 \\
\hline Land for apple 2 LHS & 30 & 67325 & 30 & 30 & 0 \\
\hline Land for apple 3 LHS & 25 & 8343025.297 & 25 & 7.8125 & 5.555555556 \\
\hline Land for apple 4 LHS & 26.66666667 & 0 & 40 & $1 E+30$ & 13.33333333 \\
\hline Land for apple 5 LHS & 20 & 3485543.75 & 20 & 26.66666667 & 20 \\
\hline Land for grapes 1 LHS & 35 & 7201.898548 & 35 & 30.41666667 & 7.275641026 \\
\hline Land for grapes 2 LHS & 30 & 0 & 30 & $1 E+30$ & $-7.10543 E-15$ \\
\hline Land for grapes 3 LHS & 25 & 9581163.69 & 25 & 0 & 4.761904762 \\
\hline Land for grapes 4 LHS & 40 & 12980.80633 & 40 & 30 & 15 \\
\hline Land for grapes 5 LHS & 20 & 4065587.5 & 20 & 13.33333333 & 20 \\
\hline Land for drupes 1 LHS & 65 & 827690.3965 & 65 & 33.18181818 & 0 \\
\hline Land for drupes 2 LHS & 60 & 5096325 & 60 & 30 & 0 \\
\hline Land for drupes 3 LHS & 55 & 13183684.9 & 55 & 5.952380952 & 3.571428571 \\
\hline Land for drupes 4 LHS & 70 & 597840.9392 & 70 & 35 & 17.5 \\
\hline Land for drupes 5 LHS & 50 & 13651262.5 & 50 & 10 & 23.33333333 \\
\hline Fertilizers 1 LHS & $-1.66619 E-09$ & -10.71428571 & 0 & $1 E+30$ & 25651.78571 \\
\hline Fertilizers 2 LHS & $-3.63798 E-12$ & -55 & 0 & $1 E+30$ & 29100 \\
\hline Fertilizers 3 LHS & $5.31873 E-09$ & -20.83333333 & 0 & $1 E+30$ & 35089.28571 \\
\hline Fertilizers 4 LHS & $5.96629 E-10$ & -9.027777778 & 0 & $1 E+30$ & 23583.33333 \\
\hline Fertilizers 5 LHS & $-1.05501 E-08$ & -56.25 & 0 & $1 E+30$ & 46400 \\
\hline Costs 1 LHS & $-8.24803 E-08$ & -0.116071429 & 0 & 317675.1374 & $1 E+30$ \\
\hline Costs 2 LHS & 0 & -0.5 & 0 & 361500 & $1 E+30$ \\
\hline Costs 3 LHS & $2.69793 E-07$ & -0.145833333 & 0 & 445089.2857 & $1 E+30$ \\
\hline Costs 4 LHS & $-1.17405 E-07$ & -0.111111111 & 0 & 290416.6667 & $1 E+30$ \\
\hline Costs 5 LHS & $2.18092 E-06$ & -0.25 & 0 & 599500 & $1 E+30$ \\
\hline Labor 1 LHS & -430.9065934 & 0 & 21 & $1 E+30$ & 451.9065934 \\
\hline Labor 2 LHS & -480 & 0 & 20.5 & $1 E+30$ & 500.5 \\
\hline Labor 3 LHS & -625 & 0 & 20 & $1 E+30$ & 645 \\
\hline Labor 4 LHS & -404.1666667 & 0 & 21.5 & $1 E+30$ & 425.6666667 \\
\hline Labor 5 LHS & -752 & 0 & 19.5 & $1 E+30$ & 771.5 \\
\hline Apple yield 1 LHS & $-7.78819 E-08$ & -16.07142857 & 0 & 299821.4286 & $1 E+30$ \\
\hline Apple yield 2 LHS & $5.82077 E-11$ & -80 & 0 & 411000 & $1 E+30$ \\
\hline Apple yield 3 LHS & $2.94473 E-07$ & -29.16666667 & 0 & 485714.2857 & $1 E+30$ \\
\hline Apple yield 4 LHS & $-9.3627 E-08$ & -13.88888889 & 0 & 231666.6667 & $1 E+30$ \\
\hline Apple yield 5 LHS & $2.45555 E-06$ & -75 & 0 & 675000 & $1 E+30$ \\
\hline Grapes yield 1 LHS & $4.81319 E-07$ & -12.5 & 0 & 463076.9231 & $1 E+30$ \\
\hline Grapes yield 2 LHS & 0 & -60 & 0 & 513000 & $1 E+30$ \\
\hline Grapes yield 3 LHS & $-1.47265 E-06$ & -20.83333333 & 0 & 607142.8571 & $1 E+30$ \\
\hline Grapes yield 4 LHS & $-1.74856 E-07$ & -11.11111111 & 0 & 432500 & $1 E+30$ \\
\hline Grapes yield 5 LHS & $3.07418 E-06$ & -50 & 0 & 845000 & $1 E+30$ \\
\hline Apricot yield 1 LHS & 0 & -53.7124311 & 0 & 1165357.143 & 0 \\
\hline Apricot yield 2 LHS & 0 & -244.782 & 0 & 1500000 & 0 \\
\hline Apricot yield 3 LHS & $-3.23541 E-06$ & -26.04166667 & 0 & 1333928.571 & $1 E+30$ \\
\hline Apricot yield 4 LHS & $1.79057 E-10$ & -48.64512122 & 0 & 980000 & $1.79057 E-10$ \\
\hline Apricot yield 5 LHS & $3.60981 E-06$ & -62.5 & 0 & 992000 & $1 E+30$ \\
\hline Peach yield 1 LHS & $-1.83983 E-05$ & -14.28571429 & 0 & 4425416.667 & $1 E+30$ \\
\hline Peach yield 2 LHS & 0 & -75 & 0 & 4896000 & $1 E+30$ \\
\hline Peach yield 3 LHS & $2.25897 E-05$ & -29.16666667 & 0 & 2328571.429 & $1 E+30$ \\
\hline Peach yield 4 LHS & $6.61286 E-06$ & -11.80555556 & 0 & 4090000 & $1 E+30$ \\
\hline Peach yield 5 LHS & $-8.29175 E-05$ & -81.25 & 0 & 5698000 & $1 E+30$ \\
\hline Plum yield 1 LHS & 0 & -21.40944838 & 0 & 3122954.545 & 0 \\
\hline Plum yield 2 LHS & 0 & -115.9303977 & 0 & 3168000 & 0 \\
\hline Plum yield 3 LHS & 0 & -121.7137391 & 0 & 418650.7937 & 0 \\
\hline Plum yield 4 LHS & 0 & -17.19900156 & 0 & 2057222.222 & 0 \\
\hline Plum yield 5 LHS & $1.87228 E-10$ & -199.9116224 & 0 & 1676818.182 & $1.87228 E-10$ \\
\hline
\end{tabular}


with membership and nonmembership degree as follows:

$$
\begin{aligned}
& \mu_{Z_{\mathrm{FP}}}(x)= \begin{cases}0, & x<588714344, \\
\frac{x-588714344}{270311656}, & 588714344 \leq x \leq 859026000, \\
1, & x=859026000, \\
\frac{1042552710-x}{183526710}, & 859026000 \leq x \leq 1042552710, \\
0, & x>1042552710,\end{cases} \\
& \nu_{Z_{\mathrm{FP}}}(x)= \begin{cases}1, & x<449017835.6, \\
\frac{859026000-x}{410008165}, & 449017835.6 \leq x \leq 859026000, \\
0, & x=859026000, \\
\frac{x-859026000}{4486493000}, & 859026000 \leq x \leq 5345519000, \\
1, & x>5345519000 .\end{cases}
\end{aligned}
$$

8.1. Interpretation and Comparison of Results. For comparison, the results obtained by optimization model considered in fuzzy environment should be compared with the linear programming in crisp environment. The general linear programming specifically designed for fruit production gives the output of $858880500 \mathrm{~kg}$ which is maximum fruit yield by consuming the available resources and inputs. The modified triangular intuitionistic fuzzy linear programming yields the result of

$$
\begin{aligned}
\breve{Z}_{\mathrm{FP}}^{I}= & (588714344,859026000,1042552710 ; \\
& 449017835.6,859026000,5345519000),
\end{aligned}
$$

which is clearly maximum fruit production output in the form of triangular intuitionistic fuzzy number. These results are further explained and demonstrated trough detailed analysis in the form of graphical representation in Figure 2 which shows the output of both techniques. The level of satisfaction increases with the production increase from 588714344 to 859026000 , reaches the maximum over 859026000 with membership degree 1, and then decreases afterwards to 1042552710 . It is obvious that degree of nonmembership decreases with the increase in membership degree simultaneously. The vertical line in the graph at 858880500 represents the results of linear programming. In comparison, the graph already shows that $145500 \mathrm{~kg}$ of yield increased by triangular intuitionistic fuzzy linear programming and the optimal region obtained from this technique is much more acceptable due to the feasibility levels at certain situations.
8.2. Postoptimality (Sensitivity) Analysis. Sensitivity analysis (postoptimality analysis) is the process of determining how changes in the optimal solution influence it, within certain limits. The sensitivity analysis is carried out by changing the coefficients of objective function and the right-hand side (RHS) values of constraints. Here, postoptimality (sensitivity) analysis of triangular intuitionistic fuzzy linear programming is assessed using the Tables 4 and 5. The solution remains optimal and feasible within the specified limits of variables and parameters. Range of optimality is dependent on the coefficients of objective function, which means that change in the coefficients of objective function affects the optimality of solution, which is represented by Table 4 . This table contains the limits for the coefficients of each variable in the form of allowable increase and decrease. For example, the limit of coefficient of $x_{1,1}$ having original value 0 is between 10082.65797 and 333727.8781 , and the solution remains optimal for this range. The cell containing value $1 E+30$ in the form of allowable increase or decrees means that there is no limit for the increase or decrease of that specific variable.

In Table 5, the range of each constraint is presented with the shadow increase in objective value, which is only valid for given ranges. A change in the right-hand side of a constraint directly changes the feasible region which perhaps influences the optimal solution. From Table 5, it is clear that our feasibility region remains feasible and the same if the constraints change within the allowable range. As observed from Table 5, the total land constraint 1 has a range between 7.275641026 and 30.41666667 in which feasibility region of the model remains unchanged. Moreover, shadow price is also given per unit increase in the right-hand side of the constraint providing improvement in the value of the optimal solution. The above analysis indicated that this technique is providing flexible optimal solution with the original data.

\section{Conclusion}

The comparison of methodologies, postoptimality (sensitivity) analysis, and compiled statistics stated that the triangular intuitionistic fuzzy linear programming is providing best results for management of real-life problems. The feasible region for optimal production in fuzzy environment remains feasible and optimal within sufficient range. In future, we can consider this model in different fuzzy environments to optimize production and observe the optimality and feasibility levels more accurately. To maintain the level of food security nationally or internationally, we can design a multilevel model in fuzzy environment for the achievement of best optimal agricultural production with least cost by consuming available resources.

\section{Data Availability}

Fruit production data were collected from local farmers to support this study.

\section{Conflicts of Interest}

The authors declare that there are no conflicts of interest regarding the publication of this article. 


\section{Authors' Contributions}

All authors contributed equally to the preparation of this manuscript.

\section{References}

[1] https://en.wikipedia.org/wiki/Agriculture.

[2] M. D. Anderson and W. Lockeretz, "Sustainable agriculture research in the ideal and in the field," Journal of Soil and Water Conservation, vol. 47, no. 1, pp. 100-111, 1992.

[3] C. Vogliano, L. Murray, J. Coad et al., "Progress towards SDG 2: zero hunger in melanesia-a state of data scoping review," Global Food Security, vol. 29, Article ID 100519, 2021.

[4] H. Calderon, P. Oscar, Y. Ricardongel et al., "A bibliometric analysis of the scientific production related to "zero hunger" as a sustainable development goal: trends of the pacific alliance towards 2030," Agriculture \& Food Security, vol. 10, no. 1, pp. 1-15, 2021.

[5] R. Christian, D. Wheeler, W. Rebecca, L. Michael, C. Matt, and A. Charlotte, "Agriculture 4.0: making it work for people, production, and the planet," Land Use Policy, vol. 100, Article ID 104933, 2021.

[6] J. Pomerleau, K. Lock, M. McKee, and D. R. Altmann, "The challenge of measuring global fruit and vegetable intake," Journal of Nutrition, vol. 134, no. 5, pp. 1175-1180, 2004.

[7] K. Siegel, M. Ali, K. Srinivasiah, N. Adithi, N. Rachel, and K. M. Venkat, "Do we produce enough fruits and vegetables to meet global health need?" PLoS One, vol. 9, no. 8, Article ID e104059, 2014.

[8] https://en.wikipedia.org/wiki/Agriculture.

[9] https://viewsweek.com/pakistan-fruit-production/.

[10] B. Ahmad, M. Anwar, B. Hammad, M. Mehdi, and T. Farooq, "Analyzing export competitiveness of major fruits and vegetables of Pakistan: an application of revealed comparative advantage indices," Pakistan Journal of Agricultural Sciences, vol. 58, no. 2, pp. 719-730, 2021.

[11] S. A. Husiani and J. Rehman, "A study on horticultural sector of Pakistan. Understanding the bottlenecks and opportunities in value-added exports of fruits and vegetables," pp. 1-64, 2020, https://invest.gov.pk/sites/default/files//PBC-Horticulture-Sector -StudyReport-compressed-compressed.pdf.

[12] H. Manzoor, M. Safyan, and F. Manzoor, "Trade competitiveness of Pakistan's fruits and vegetables in world market," 2020.

[13] R. Moeini and M. Soltani-nezhad, "Extension of the constrained gravitational search algorithm for solving multireservoir operation optimization problem," Journal of Environmental Informatics, vol. 36, no. 2, 2020.

[14] P. Udmale, I. Pal, S. Szabo, M. Pramanik, and A. Large, "Global food security in the context of COVID-19: a scenariobased exploratory analysis," Progress in Disaster Science, vol. 7, Article ID 100120, 2020.

[15] L. V. Kantorovich, "Mathematical methods of organizing and planning production," Management Science, vol. 6, no. 4, pp. 366-422, 1960.

[16] H. A. Eiselt and C. L. Sandblom, Linear Programming and its Applications, Springer Science \& Business Media, Berlin, Germany, 2007.

[17] O. A. Solaja, J. A. Abiodun, M. A. Abioro, J. E. Ekpudu, and O. M. Olasubulumi, "Application of linear programming in production planning," International Journal of Applied Operational Research, vol. 9, no. 3, pp. 11-19, 2019.
[18] G. Vico and R. Bodiroga, "Tools for planning in agriculture-linear programming approach," Agri-Base, 2017.

[19] M. Li, V. P. Singh, Q. Fu, D. Liu, T. Li, and Y. Zhou, "Optimization of agricultural water-food-energy nexus in a random environment: an integrated modelling approach," Stochastic Environmental Research and Risk Assessment, vol. 35, no. 1, pp. 3-19, 2021.

[20] M. G. Muluneh, "Impact of climate change on biodiversity and food security: a global perspective-a review article," Agriculture \& Food Security, vol. 10, no. 1, pp. 1-25, 2021.

[21] A. Gupta, C. P. Sawant, K. V. R. Rao, and A. Sarangi, "Results of century analysis of rainfall and temperature trends and its impact on agriculture production in Bundelkhand region of Central India," Mausam, vol. 72, no. 2, pp. 473-488, 2021.

[22] L. A. Zadeh, "Fuzzy sets," Information and Control, vol. 8, no. 3, pp. 338-353, 1965.

[23] K. T. Atanassov, "Intuitionistic fuzzy sets," Fuzzy Sets and Systems, vol. 20, no. 1, pp. 87-96, 1986.

[24] H.-J. Zimmermann, "Description and optimization of fuzzy systems $\dagger, "$ International Journal of General Systems, vol. 2, no. 1, pp. 209-215, 1975.

[25] R. Ghanbari, K. Ghorbani-Moghadam, N. Mahdavi-Amiri, and B. De Baets, "Fuzzy linear programming problems: models and solutions," Soft Computing, vol. 24, pp. 1-31, 2019.

[26] Z. Luo, Y. Xie, L. Ji, Y. Cai, Z. Yang, and G. Huang, "Regional agricultural water resources management with respect to fuzzy return and energy constraint under uncertainty: an integrated optimization approach," Journal of Contaminant Hydrology, vol. 242, Article ID 103863, 2021.

[27] D. V. Morankar, K. Srinivasa Raju, and D. Nagesh Kumar, "Integrated sustainable irrigation planning with multiobjective fuzzy optimization approach," Water Resources Management, vol. 27, no. 11, pp. 3981-4004, 2013.

[28] S. K. Bharati and S. R. Singh, "Intuitionistic fuzzy optimization technique in agricultural production planning: a small farm holder perspective," International Journal of Computer Applications, vol. 89, no. 6, pp. 17-23, 2014.

[29] M. C. J. Anand and J. Bharatraj, "Theory of triangular fuzzy number," Proceedings of NCATM, vol. 80, 2017.

[30] https://www.sciencedirect.com/topics/computer-science/wei ghted-sum-method.

[31] S. Khan, S. Shahab, M. I. Fani, A. Wahid, M. Hasan, and A. Khan, "Climate and weather condition of Balochistan province, Pakistan," Internation Journal of Economic and Enivronmental Geology, vol. 12, no. 2, pp. 65-71, 2021.

[32] https://en.wikipedia.org/wiki/Balochistan. 